\section{Early Detection of Productive Baculovirus DNA Transfection}

\section{BioTechniques 29:430-434 (September 2000)}

The most widely studied baculovirus, the Autographa californica $\mathrm{M}$ nucleopolyhedrovirus (AcMNPV), is a large, enveloped DNA virus that infects lepidopteran larvae (8). This virus is commonly used as a eukaryotic vector to express heterologous genes in cultured insect cells and insect larvae $(1,3,15)$. Baculovirus expression systems offer several advantages over other expression systems, among which are the capacity for large DNA insertions, high levels of recombinant protein synthesis, production of proteins that are similar in biological activity, stability, posttranslational modifications (e.g., glycosylation, phosphorylation, etc.), structure and immunological activity, as compared to naturally occurring proteins $(2,7,14,15)$. In some cases, the recombinant proteins are targeted to appropriate cellular compartments (1).

Since the protective protein occlusion matrix (polyhedrin) is nonessential for AcMNPV propagation in cell culture, the polyhedrin gene in the baculovirus expression vector systems is usually replaced by heterologous genes that are overexpressed under the transcriptional control of the strong polyhedrin promoter, which is activated at later stages of the viral replication cycle (10). The early systems relied on substitution of the polyhedrin gene with the foreign gene by homologous recombination, between wild-type virus DNA and the heterologous gene construct after co-transfection of these DNAs into insect cells. In this case, the number of recombinant plaques is usually low, requiring sequential plaque assays and viral amplification to purify recombinant virus and obtain sufficient amount of virus for protein expression $(1,7,9,15)$. Also, it is difficult even for experienced researchers to distinguish occlusion-minus recombinant plaques from noninfected cells and to monitor cell-density decreases and cell-size increases in cultures infected with recom binant baculovirus (2).
The recently developed BAC-TO$\mathrm{BAC}^{\mathrm{TM}}$ system (Life Technologies, Rockville, MD, USA) is based on sitespecific transposition of an expression cassette from a plasmid (pFAST-BAC ${ }^{\mathrm{TM}}$ ) to a baculovirus shuttle vector (bacmid) that is propagated in E. coli. The foreign gene is expressed after transfection of the recombinant bacmid DNA into insect cells, resulting in a recombinant baculovirus that may be used to infect other insect cell cultures $(1,5,9,11$, 14). This improvement allows a more rapid production of the recombinant protein without isolation of viral plaques. However, since the polyhedrin gene has been deleted from the bacmid, only subtle morphological differences can be detected between infected and uninfected cells using either parental or recombinant baculovirus, making it difficult to confirm productive transfection or infection. To distinguish between infected and uninfected cells, some markers have been proposed such as $\beta$-galactosidase, luciferase and fluorescent proteins $(2,15)$. These markers are effective, but they rely on specially constructed vectors and specific assays that can be cumbersome and time consuming. They also generate fusion proteins, which may not be desirable.

Based on our experience with animal viruses, we propose two rapid and practical methods that allow confirmation of productive transfection with bacmid DNA: (i) subculture of the transfected Spodoptera frugiperda (Sf9) cells that leads to a dramatic amplification of the cytopathic effect; and (ii) PCR amplification of the recombinant baculovirus DNA present in culture supernatants from the first virus amplification. These methods allow early detection of any problem in the bacmid transfection, thus avoiding the waste of time and reagents involved in subsequent steps.

Results presented here were obtained using recombinant baculovirus constructs encoding the complete sequence of the glycoprotein $\mathrm{C}(\mathrm{gC})$ gene from bovine herpesvirus 1 (BHV-1). Two different inserts were separately subcloned into the pFASTBAC HT vector (Life Technologies): a 2.4-kb NcoI/EcoRI fragment containing the complete sequence of $\mathrm{gC}$, and a $1.3-\mathrm{kb}$ NcoI/SalI fragment containing a partial sequence of $\mathrm{gC}$ that lacks the transmembrane terminal portion (manuscript in preparation). The resulting plasmids (pFASTBAC-HT-gC and pFASTBAC-HT-partial gC) were prepared by alkaline lysis DNA purification (12). Recombinant plasmids were transformed into DH10BAC ${ }^{\mathrm{TM}}$-competent bacteria (Life Technologies), and white colonies (with transposed recom binant bacmid) were selected and grown overnight for recombinant bacmid DNA purification, according to the BAC-TO-BAC baculovirus expression system instructions. Correct transposition of $\mathrm{gC}$ sequences from $\mathrm{pFASTBAC}$ HT into the bacmid was confirmed by automated DNA sequencing.

Bacmid DNA isolation and cell transfection were performed as described in the BAC-TO-BAC manual. Recombinant bacmid DNA was isolated from $1.5-\mathrm{mL}$ cultures using the alkaline lysis protocol. The presence and integrity of bacmid DNA in these preparations were analyzed by electrophoresis of 4 $\mu \mathrm{L}$ of each miniprep through a $0.8 \%$ agarose gel in 1× TAE (12) and stained with ethidium bromide. Bacmid DNA was directly used to transfect Sf9 cells.

Transfection of $9 \times 10^{5} \mathrm{Sf} 9$ cells $/ 35$ $\mathrm{mm}$ dish was performed using $5 \mu \mathrm{L}$ recombinant bacmid DNA and $6 \mu \mathrm{L}$ CellFECTIN $^{\mathrm{M}}$ reagent in $1 \mathrm{~mL}$ SF900 II SFM reagent (both from Life Technologies) without antibiotics. After $5 \mathrm{~h}$, the medium was changed to $2 \mathrm{~mL}$ TNMFH medium (Grace's insect cell medium supplemented with $4 \mathrm{~g} / \mathrm{L}$ yeastolate, $3.3 \mathrm{~g} / \mathrm{L}$ lactoalbumin hydrolysate (Life Technologies) plus $10 \%$ fetal calf serum (Cultilab, Campinas, Brazil), and cells were maintained at $28^{\circ} \mathrm{C}$. Untransfected cells and cells transfected with empty bacmid DNA (without transposed DNA) were used as transfection controls. At $72 \mathrm{~h}$ after transfection, the medium was recovered, clarified by centrifugation at $800 \times \mathrm{g}$ for $5 \mathrm{~min}$ and stored as viral stocks, protected from light at $4^{\circ} \mathrm{C}$.

After collection of transfected Sf9 cell medium, we suggest subculturing the transfected cells (a blind passage) as a method to rapidly amplify viral titers and enhance the cytopathic effect caused by the recombinant baculovirus generated during transfection. The cells from each transfected culture were resuspend- 
ed into fresh TNM-FH medium using a Pasteur pipet, transferred to a $25-\mathrm{cm}^{2}$ culture flask and incubated at $28^{\circ} \mathrm{C}$ for $48 \mathrm{~h}$. Cultures were then observed under a Nikon Diaphot phase contrast microscope $(100 \times$ magnification) to evaluate the baculoviral cytopathic effect generated from productive transfections.

Within $48 \mathrm{~h}$ of subculturing, the cytopathic effect is dramatically enhanced in cultures containing cells transfected with recombinant bacmid DNA (Figure 1, C and D). Subcultures of untransfected cells (Figure 1A, negative control) displayed mostly attached and spread-out cells, and subcultures of cells transfected with the empty bacmid DNA displayed low density of poorly adhered cells (Figure 1B, positive control). The positive results presented in Figure 1, C and D, indicate successful transfection with titers of 100 plaqueforming units $/ \mathrm{mL}$ (pfu/mL) or higher, suggesting that it is valid to proceed to further steps for protein expression. On the other hand, transfection assays performed with damaged bacmid DNA or with low-viability Sf9 cells yielded subcultures with no cytopathic effect (data not shown). The latter could then be prematurely interrupted, avoiding the waste of time and reagents.

The transfection supernatants were used to infect Sf9 cells and to amplify viral stocks, according to the BAC-TOB AC manual. To amplify viral stocks, 1 $\times 10^{6} \mathrm{Sf} 9$ cells/35-mm dish were grown overnight with $2 \mathrm{~mL}$ TNM-FH medium at $28^{\circ} \mathrm{C}$ before viral inoculation. At the moment of infection, the medium was removed, and $1 \mathrm{~mL}$ TNM-FH medium containing $10 \mu \mathrm{L}$ viral stock obtained upon transfection was added to the Sf9 cells. Infected cultures were incubated under agitation for $1 \mathrm{~h}$ using an orbital platform. According to the BAC-TOBAC manual, viral titers of $2-4 \times 10^{7}$ $\mathrm{pfu} / \mathrm{mL}$ can be expected in transfection; therefore, the inoculum for viral amplification corresponds to a multiplicity of infection (MOI) equal to or lower than 0.1 . Following incubation, an additional volume $(1 \mathrm{~mL})$ of medium was added per dish and cultures were incu- bated for 48 h. Clarified culture supernatants were maintained at $4{ }^{\circ} \mathrm{C}$ and protected from light.

As a second approach to confirm productive transfection, we used PCR analysis of DNA obtained from amplified baculovirus stocks. To this end, a simple small-scale procedure is suggested to prepare baculovirus DNA for PCR. Some care was taken to allow viral DNA amplification and to avoid interference of any residual DNA remaining from the transfection step. Baculovirus DNA templates for PCR amplification were prepared from infected (not transfected) cultures and sedimented baculovirus particles (not culture medium). Baculovirus present in $50 \mu \mathrm{L}$ culture supernatant were concentrated at $12000 \times \mathrm{g}$ for $10 \mathrm{~min}$ in a microcentrifuge. The supernatant was carefully aspirated using a fine tip without disturbing the (invisible) viral pellet. A volume $(25 \mu \mathrm{L})$ of proteinase $\mathrm{K}$ buffer [10 mM Tris ( $\mathrm{pH} 7.8), 5 \mathrm{mM}$ EDTA and $0.5 \%$ SDS] containing 50 $\mu \mathrm{g} / \mathrm{mL}$ proteinase $\mathrm{K}$ (12) was added to the pellet to digest viral proteins for $1 \mathrm{~h}$ at $56^{\circ} \mathrm{C}$ and at $95^{\circ} \mathrm{C}$ for $20 \mathrm{~min}$ for inactivation of the enzyme before PCR.

For PCR amplification $(25-\mu \mathrm{L}$ volume), BHV-1 gC gene PCR was performed with specific primers (13), in a PTC-200 ${ }^{\mathrm{TM}}$ Thermal Cycler (MJ Research, Waltham, MA, USA). The reaction mixture contained $10 \mathrm{mM}$ Tris$\mathrm{HCl}$ (pH 8.3), $10 \mathrm{mM} \mathrm{KCl}, 1.5 \mathrm{mM}$

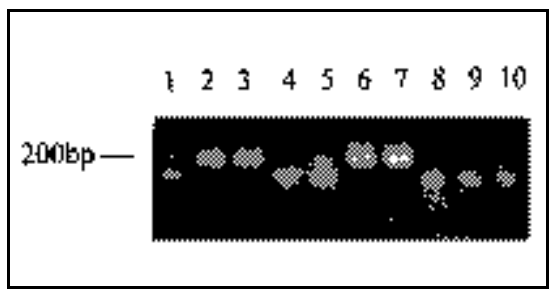

Figure 2. Agarose gel electrophoresis of genespecific PCR products (173 bp) obtained from DNA preparations of recombinant baculovirus stocks. Molecular weight marker 100bp ladder (Life Technologies) (lane 1) and PCR products from: complete and partial $\mathrm{gC}$ recombinant bacmid DNA (lanes 2 and 3, respectively, positive controls), nonproductive transfections of complete and partial $\mathrm{gC}$ recombinant bacmid DNA (lanes 4 and 5, respectively), productive transfections of complete and partial $\mathrm{gC}$ recombinant bacmid DNA (lanes 6 and 7, respectively), empty bacmid DNA (lane 8, negative control), productive transfection of empty bacmid DNA (lane 9, negative control) and untransfected Sf9 cells (lane 10, negative control).
Figure 1. Photomicrographs, taken under a Nikon Diaphot phase contrast microscope of subcultures generated from Sf9 cells, transfected using the BAC-TO-B AC system. Dramatic differences in cell density and adhesion to the substrate are visualized after $48 \mathrm{~h}$. Untransfected Sf9 cell subcultures (A), subcultures from Sf9 cells transfected with empty bacmid DNA (B) and subcultures from Sf9 cells transfected with recombinant bacmid containing two different constructs of the BHV-1 gC gene: com plete gene $(C)$ and partial gene (D) $(100 \times$ magnification $)$. 
$\mathrm{MgCl}_{2}, 0.2 \mathrm{mM}$ each dATP, dTTP, dGTP and dCTP, $0.2 \mu \mathrm{M}$ each primer and $0.5 \mathrm{U}$ Taq DNA polymerase (Amersham Pharmacia Biotech, Uppsala, Sweden). For PCR amplifications, $5 \mu \mathrm{L}$ each recombinant baculovirus DNA preparation was used as template. As positive controls, $1 \mu \mathrm{L}$ each recombinant bacmid DNA was used. Empty bacmid DNA, Sf9 cells transfected with empty bacmid DNA and untransfected Sf9 cells were used as negative controls. The entire volume $(25 \mu \mathrm{L})$ of each PCR sample was analyzed by electrophoresis through a $1 \%$ agarose gel in $1 \times$ TAE (12) and stained with ethidium bromide. PCR products of $173 \mathrm{bp}$ are expected in both constructs of the BHV-1 gC gene (complete and partial sequences).

The results indicate the presence of an intense band, corresponding to the amplification products, only in samples originating from productive transfections (Figure 2, lanes 6 and 7) and positive controls (Figure 2, lanes 2 and 3). No or weak amplification coincided with nonproductive transfections (Figure 2, lanes 4 and 5) that led to nondetectable recombinant protein expression in SDS-PAGE or Western blot (data not shown). Lanes 4 and 5 represent a negative diagnostic result (nonproductive transfection), and lanes 6 and 7 represent a positive diagnostic result (productive transfection). All templates came from Sf9 cells transfected with the same DNA preparation, used in lanes 2 and 3 as a positive control for the presence of primed sequence.

The results of the amplification of specific small fragments were highly reproducible in a large $(>10)$ number of independent experiments. On the other hand, the use of M13 primers (14) for full-length insert amplification causes weak and inconsistent results. A previously published pair of degenerate primers, designed to amplify a 575-bp fragment of different baculoviruses, could be useful in monitoring the release of wild-type and genetically engineered baculoviruses (4).

The procedure suggested for the BAC-TO-BAC expression system (subculture of transfected cells and PCR from baculovirus DNA) alone cannot guarantee recombinant protein expression or its functional activity. But it can provide early and direct detection of baculovirus generated by transfection at the initial and rate-limiting steps. Eventual problems occurring at this early stage could be rapidly detected and avoid the waste of time and reagents involved in further experiments. Using this scheme, it was possible to obtain the first qualitative analysis of recombinant protein expression by Western analysis within 6-7 days of recombinant bacmid transfection.

Using other baculovirus expression systems based on homologous recombination, the subculturing of transfected insect cells as suggested in this work allows the confirmation of productive transfection by visualization of the cytopathic effect. However, because of the presence of both wild-type and recom binant baculovirus in the stock, it is still necessary to isolate single recombinant plaques. The baculovirus DNA purification and PCR procedures described here may be useful in subsequent steps to confirm recombinant viral clones.

\section{REFERENCES}

1.Anderson, D., R. Harris, D. Polayes, V. Ciccarone, R. Donahue, G. Gerard, J. Jessee and V. Luckow. 1995. Rapid generation of recombinant baculovirus and expression of foreign genes using the BAC-TO-BAC ${ }^{\mathrm{TM}}$ baculovirus expression system. Focus 17:53-58.

2.Cha, H.J., T. Gotoh and W.E. Bentley. 1997. Simplification of titer determination for recombinant baculovirus by green fluorescent protein marker. BioTechniques 23:782-786.

3.Das, R.H., O.B. Bansal, A.K. Behera, Y. Durgaprasad, M. Kumar and A. Bali. 1996. Rapid and gentle method for the isolation of DNA from nuclear polyhedrosis viruses. BioTechniques 20:364-368.

4.de Moraes, R.R. and J.E. Maruniak. 1997. Detection and identification of multiple baculoviruses using the polymerase chain reaction (PCR) and restriction endonuclease analysis. J. Virol. Methods 63:209-217.

5.Donahue, Jr., R.A. 1995. Use of PCR to identify recombinant bacmid clones from the BCTO-BAC $^{\text {TM }}$ system. Focus 17:102-103.

6.Hecht, P., M. Engels, E. Loepfe and M. Ackermann. 1995. Comparison of the glycoprotein $\mathrm{gC}$ genes of bovine and caprine herpesviruses, p.147-152. In M. Schwyzer, M. Ackermann, G. Bertoni, R. Kocherhans, K. McCullough, M. Engels, R. Wittek and R. Zanoni (Eds.), Immunobiology of Viral Infections. Proc. 3rd Congress Europ. Soc. Vet. Virol.; Fondation Marcel Merieux, Lyon.

7.Kitts, P.A. and G. Green. 1999. An immunological assay for determination of baculovirus titers in 48 hours. Analytical Biochemistry 268:173-178.
8.Lanier, L.M., K. Storm, A. Shafaie and L.E. Volkman. 1997. Copper treatment increases recombinant baculovirus production and polyhedrin and p10 expression. BioTechniques 23:728-735.

9.Luckow, V.A., S.C. Lee, G.F. Barry and P.O. Olins. 1993. Efficient generation of infectious recombinant baculoviruses by site-specific transposon-mediated insertion of foreign genes into a baculovirus genome propagated in Escherichia coli. J. Virol. 67:4566-4579.

10.O'Reilly, D.R., L.K. Miller and V.A. Luckow. 1992. Baculovirus Expression Vectors: A Laboratory Manual. Freeman, New York.

11.Polayes, D., R. Harris , D. Anderson and V. Ciccarone. 1996. New baculovirus expression vectors for the purification of recombinant proteins from insect cells. Focus 18:10-13.

12.Sambrook, J., E.F. Fritsch and T. Maniatis. 1989. Molecular Cloning: A Laboratory Manual, Second edition, CSH Laboratory Press, Cold Spring Harbor, NY.

13.Van Engelenburg, F.A., R.K. Maes, J.T. van Oirschot and F.A. Rijsewijk. 1993. Development of a rapid and sensitive polymerase chain reaction assay for detection of bovine herpesvirus type 1 in bovine semen. J. Clin. Microbiol. 31:3129-3135.

14.Webb, A.C., M.K. Bradley, S.A. Phelan, J.Q. Wu and L. Gehrke. 1991. Use of the polymerase chain reaction for screening and evaluation of recombinant baculovirus clones. BioTechniques 1 1:512-519.

15.Wilson, L.E., N. Wilkinson, S.A. Marlow, R.D. Possee and L.A. King. 1997. Identification of recombinant baculoviruses using green fluorescent protein as a selectable marker. BioTechniques 22:674-681.

This work was supported by FAPESP, CNPq, ICGEB, CAPES, PRP-USP, FAPE$M I G$ and PADCT-SBIO. Address correspondence to Dr. Mari Cleide Sogayar, Departamento de Bioquímica - Instituto de Química, Universidade de São Paulo, Caixa Postal 26.077, CEP 05513-970 - São Paulo-SPBrazil.e-mail: mcsoga@iq.usp.br

Received 19 August 1999; accepted 3 April 2000.

\section{Áurea Valadares Folgueras- Flatschart, Roberto Becht Flatschart, Maurício Resende and Mari Cleide Sogayar Instituto de Química Universidade de São Paulo São Paulo, Brazil}

